\title{
Kahramanmaraş Yöresinde Doğal Olarak Yayılış Gösteren Bazı Endemik Bitki Türleri Üzerine Taksonomik Gözlemler
}

\author{
Yusuf Ziya KOCABAŞ \\ KSÜ, Türkoğlu MYO, Tıbbi ve Aromatik Bitkiler Bölümü, Kahramanmaraş, Türkiye \\ kocabasyz@ksu.edu.tr
}

\section{Özet}

Bu araştırmada; Türkiye Bitkileri Kırmızı Kitabına göre IUCN tehlike kategorisi EN olan Ajuga relicta P.H.Davis (Lamiaceae), CR olan Astragalus akmanii Aytaç \& H.Duman (Fabaceae) ve VU kategorisinde değerlendirilen Gypsophila nodiflora (Boiss.) Barkoudah (Caryophyllaceae) ile değerlendirme kriteri olmayan Salvia marashica İlçim, Celep \& Doğan (Lamiaceae) ve Stachys marashica İlçim, Çenet \& Dadandı (Lamiaceae)'ya ait türlerinin morfolojik özellikleri ve yetişme ortamlarına ait bilgiler verilmiştir.

Anahtar Kelimeler: Nadir bitkiler, Ekoloji, Morfoloji, Kahramanmaraş.

\section{The Taxonomic Observations on Some Endemic Plant Species Growing in Kahramanmaras Province}

\begin{abstract}
In this research, the morphological features and habitats characteristics of Ajuga relicta P.H.Davis (Lamiaceae) EN category, Astragalus akmanii Aytaç \& H.Duman (Fabaceae) CR kategory, Gypsophila nodiflora (Boiss.) Barkoudah (Caryophyllaceae) VU kategory treated but were not evaluated Salvia marashica llcim, Celep \& Doğan (Lamiaceae) and Stachys marashica llcim, Çenet \& Dadandı (Lamiaceae) any category according to Red Data Book of Turkish Plants, are presented.
\end{abstract}

Keywords: Rare Plants, Ecology, Morphology, Kahramanmaraş.

\section{Gíriş}

Türkiye sahip olduğu zengin bitki çeşitliliği ve farklı vejetasyon tipleri ile Dünyada eşsiz bir konumdadır. Bu durum; değişik toprak tiplerinin varlığı, farklı makro ve mikro iklim karakteri; coğrafik konumu, jeolojik, topoğrafik yapı ve üç ayrı bitki coğrafyasının kesişme noktasında yer almasının sonucudur. Anadolu'nun Avrupa ve Asya kıtası arasında köprü konumunda olması endemizm oranının ve biyoçeşitliliğin de yüksek olmasına neden olmaktadır [1]. Türkiye florasındaki tür sayısı 13.055, endemik tür sayısı ise 3035 olup oranı \% 31.12'dir [2]. Türkiye florasında yer alan birçok türün varlığına günümüzde yapılan flora çalışmalarında rastlanamamaktadır, ayrıca birçok nadir takson da yok olma tehlikesi ile karşı karşıyadır. Türkiye Bitkileri Kırmızı Kitabı'nda bitki taksonlarına ait farklı seviyelerde tehlike kategorileri belirtilmiştir [3]. Türlere ait tehlike durumlarını tanımlamada kullanılan kategoriler şöyledir; CR (Critically endangered): Çok tehlikede, EN (Endangered): Tehlikede, VU (Vulnerable): Zarar görebilir, LR (Lower risk): Az tehdit altında, DD (Data deficient): Eksik veri. Bu 
eserde; Ajuga relicta P.H.Davis (EN) kategorisinde, Astragalus akmanii Aytaç \& H.Duman (CR) kategorisinde, Gypsophila nodiflora (Boiss.) Barkoudah (VU) kategorisinde değerlendirilmiş, Salvia marashica İlçim, Celep \& Doğan ve Stachys marashica İlçim, Çenet \& Dadandı' ya ait bir değerlendirme kriteri yoktur. Ajuga L. (Lamiaceae) cinsi üyeleri Asya, Afrika, Avrupa, Avustralya ve Kuzey Amerika'da doğal olarak bulunmakta ve süs bitkisi olarak yetiştirilmektedir. Ajuga cinsi Türkiye'de 13 tür ve 10 alt tür olmak üzere toplam 23 takson ile temsil edilmektedir [4]. Türkiye'de bu cins üyeleri diüretik, adet söktürücü, yara iyileştirici olarak tıbbi amaçlarla kullanılmaktadır [5]. Ajuga relicta P.H.Davis; 1907 yılında Kahramanmaraş ili Ahırdağı mevkiinden toplanmış, 1997 yılında aynı ilde Çimen Dağında yapılan floristik çalışmaya kadar izine rastlanmamıştır [6]. Astragalus L. (Fabaceae) cinsi, yaklaşık 3000 taksona sahip Dünya'da en büyük cinslerden biridir [7]. Türkiye'de yaklaşık 450 taksonun bulunduğu, endemizm oranının da $\% 48$ olduğu bildirilmiştir [8, 9]. Gypsophila L. (Caryophyllaceae) cinsi, Türkiye florasında 59 takson ile temsil edilmektedir [10, 11]. Çöven olarak isimlendirilen bu cinsin rizomlarından elde edilen ekstrakt öksürük ve solunum sistemleri rahatsızlıklarında, temizlik ürünlerinde, sabun ve helva üretiminde kullanılmaktadır [12]. Gypsophila nodiflora (Boiss.) Barkoudah, ilk kez Besni-Malatya arasından 1835 yılında toplanmış, 1843 yılında Saponaria nodiflora Boiss.'nın sinonimi yapılmış, Barkoudah tarafından tür olarak tanımlanmıştır [13]. Salvia L. (Lamiaceae) cinsinin gen merkezi Asya kıtasıdır. Cins Türkiye'de 97 takson ile temsil edilmektedir [14]. Salvia üyeleri tüm dünyada antibakteriyal, antioksidan, antitümör etkisinden dolayı geleneksel tıp alanında, park ve bahçelerde süs bitkisi olarak kullanılmaktadır [15, 16]. Salvia marashica İlçim, Celep \& Doğan, Kahramanmaraş ilinden toplanarak 2009 yılında yeni tür olarak tanımlanmıştır [17]. Stachys (Lamiaceae) cinsi Türkiye'de 90 tür (115 takson) ile temsil edilmekte olup endemizm oranı \% 47'dir. Stachys türleri karaciğer hastalıklarında ve kolesterolün düşürülmesinde kullanılmaktadır. Kahramanmaraş ilinin Andırın ilçesinde yayılış gösteren Stachys marashica İlçim, Çenet \& Dadandı 2008 yılında yeni tür olarak tespit edilmiştir [18]. Bu çalışmada, Ajuga relicta P.H.Davis, Astragalus akmanii Aytaç \& H.Duman, Gypsophila nodiflora (Boiss.) Barkoudah, Salvia marashica İlçim, Celep \& Doğan ve Stachys marashica İlçim, Çenet \& Dadandı türlerinin morfolojik ve taksonomik özellikleri ve ekolojilerine ait bilgiler verilmiş, tehlike kategorileri belirtilmiş ve bu nadir türlerin tanıtılarak koruma yöntemlerine yönelik çalışmalara katkı sağlamak amaçlanmıştır.

\section{MALZEME VE YÖNTEM}

Araştırmanın materyalini oluşturan bitki örnekleri, 2018-2019 yılları vejetasyon dönemlerinde Kahramanmaraş il sınırları içinde topladığımız Ajuga relicta, Astragalus akmanii, Gypsophila nodiflora, Salvia marashica, ve Stachys marashica türlerine ait bitki örnekleri oluşturmaktadır. Bitki örneklerini toplamak için türlerin tip lokalitelerindeki adreslere arazi gezileri düzenlenmiş ve türlerin tüm özelliklerini yansıtan örnekler toplanmıştır. Türlerin habitatlarına ait özellikler ile çevresinde bulunan diğer taksonlara ait bilgiler kayıt edilmiştir. Türlere ait tehlike kategorilerini belirlemek amacı ile birey sayısı, ekolojik yapı ve tehdit unsurları tespit edilmiştir. Herbaryum tekniklerine göre kurutulan bitki örneklerinin teşhisleri Türkiye Florasından yararlanılarak yapılmıştır [1, 10, 11, 19]. Morfolojik karakterleri belirlemek amacıyla her tür için 15 örnek üzerinde ölçüm ve gözlemler yapılmışıtır. Arazi gözlemleri ve örnekler üzerinde yapılan incelemeler sonucunda türlere ait taksonomik ve ekolojik bulgular belirtilmiştir. İncelenen türlere ait örnekler KSÜ Türkoğlu Meslek Yüksek Okulu Herbaryumunda muhafaza edilmektedir.

\section{BULGULAR VE TARTIŞMA}

- Ajuga relicta P.H.Davis in Notes Roy. Bot. Gard. Edinburgh, 38: 444, 1980, (Şekil 1).

Bitki çok yıllık otsu olup, gövde $30 \mathrm{~cm}$ den uzundur. Yapraklar 25-50 mm, triangular ve ampleksikaul şekilde olup tüysüz yapıdadır. Çiçekler uçlarda 8-12 cm uzunluğunda spika şeklinde, vertisillatlar 6-12 çiçeklidir. Sepaller 8-11 mm boyutlarındadır ve glandular tüylüdür. Petaller beyaz-krem renkli, yaklaşık $16 \mathrm{~mm}$ boyutunda ve bilabiattır. Nutletler $3.2 \times 1.5 \mathrm{~mm}$ reticulat ya da rugulose yüzeye sahiptir. 
- Tip örneği: C6 Kahramanmaraş: Ahır dağı, 1830 m, 17.07.1907, Haradjian 1573.

- Toplanılan yer: C6 Kahramanmaraş: Çimen dağı, Yavşan tabiat parkı batısı, K 37. 475782 D $36.692967^{\circ}$, YZK-980.

- Çiçek açma zamanı: Mayıs-Haziran

- Yetişme ortamı: Cedrus libani ve Abies cilicica ormanı açıklıkları, kahverengi orman toprakları.

- Yetişme yükseltisi: 1550-1600 m.

- Çevresindeki taksonlar: Abies cilicica (Ant. \& Kotschy) Carr. subsp. cilicica; Cedrus libani A. Rich.; Rumex nepalensis Sprengel, Astragalus fraxinifolius DC., Taraxacum bithynicum DC.; Solenanthus stamineus (Desf.) Weltst.

- Endemizm durumu: Endemik

- Fitocoğrafik bölgesi: Doğu Akdeniz elementi

- Tehlike kategorisi: EN
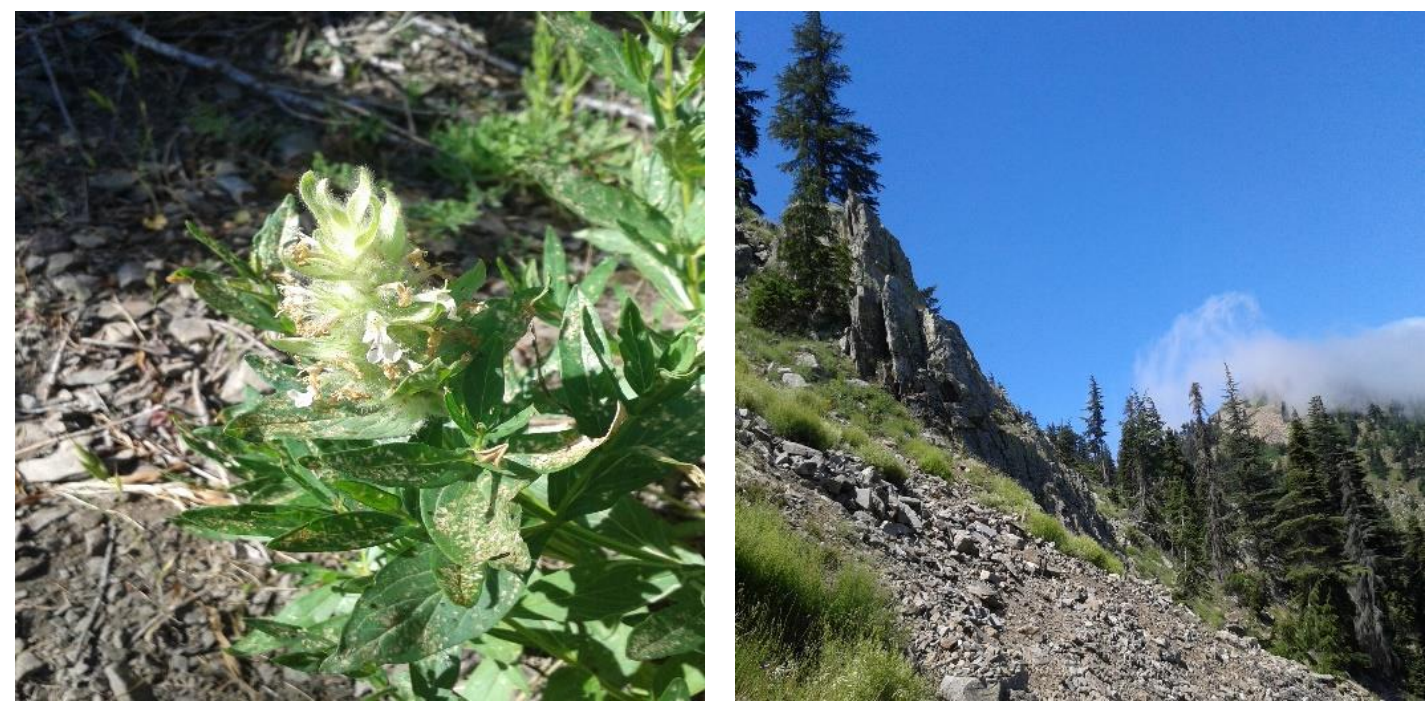

Şekil 1. Ajuga relicta'ya ait genel görünüm ve yetiştiği ortam

- Astragalus akmanii Aytaç \& H.Duman in Turk. J. Bot. 19: 477, f. 1 (1995), (Şekil 2).

Bitki 5-12 cm, yatık yada dik gövdeli, rizomlu ve sık uzun beyaz tüylüdür. Yapraklar 3-8 cm; oblonglanceolate șekillidir. Yaprak sap $3 \mathrm{~cm}$ ye kadar, yaprakçıklar 7-13 parçalı ve sık uzun beyaz tüylüdür. Çiçek sapları 3-8 cm beyaz tüylüdür. Çiçek kümesi kapitat şekilde ve 15-50 çiçeklidir. Şeritsi brakteler 4-6 mm. Sepal 9-12 mm; dişler 4-8 mm. Petal beyaz yada krem, stilus $5 \mathrm{~mm}$, Meyve 19-15 x 8-10 mm, beyaz tüylü; gaga 4-6 mm, tohumlar kahverengidir.

- Tip örneği: C6 Kahramanmaraş: Ahır Dağı. Karagöl mevkii. 1750-1800 m, 31 v11 1991. Z. Aytaç, 4219 \& H. Duman.

- Toplanılan yer: C6 Kahramanmaraş: Ahır dağı, Yedi kuyular kayak merkezi batısı, 37.637508 , D $37.032979^{\circ}$, YZK-2273.

- Çiçek açma zamanı: Temmuz- Ağustos

- Yetişme ortamı: Kireçli ve hareketli yamaçlar

- Yetişme yükseltisi: 1600-1900 m.

- Çevresindeki taksonlar: Centarurea triumfetii All., Ajuga chamaepitys subsp. euphratica P. H. Davis, Nepeta italica L., Erysimum smyrnaeum Boiss. \& Balansa

- Endemizm durumu: Endemik

- Fitocoğrafik bölgesi: İran-Turan elementi.

- Tehlike kategorisi: CR 

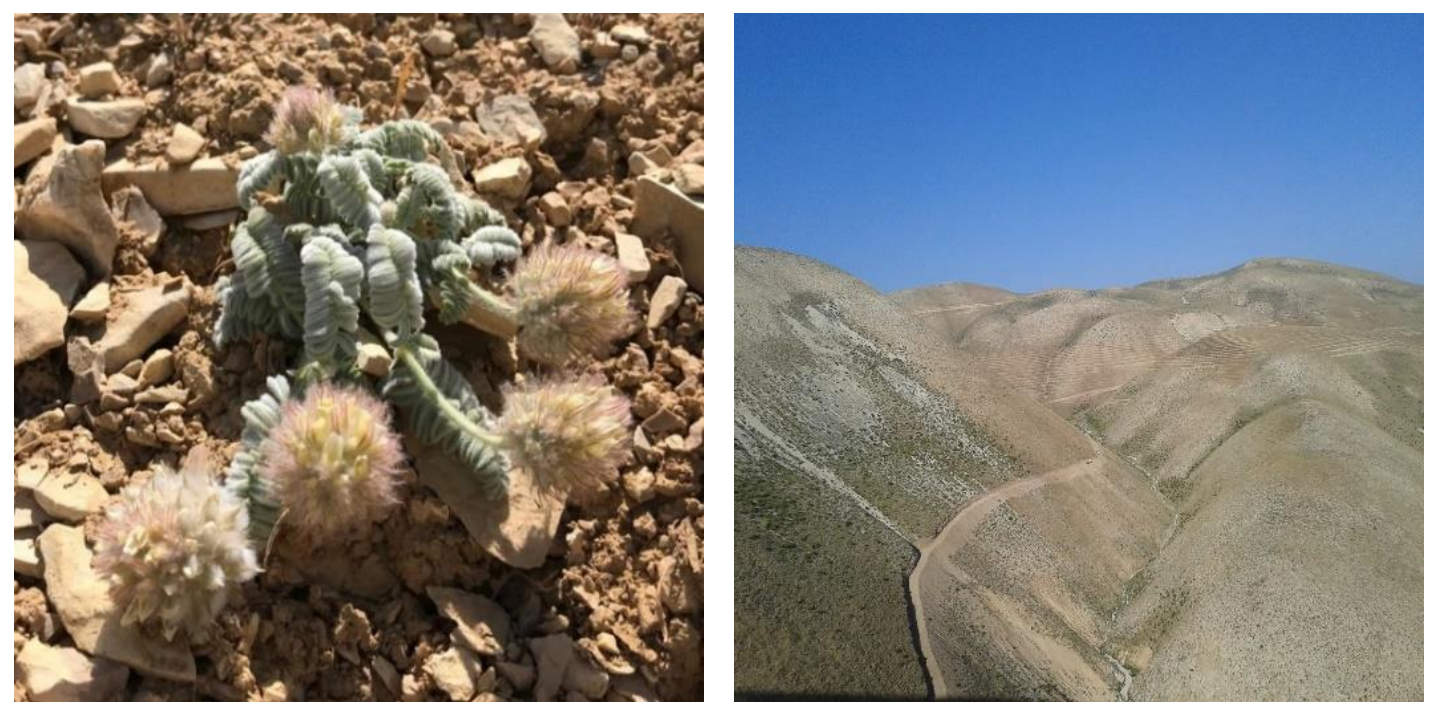

Şekil 2. Astragalus akmanii'ye ait genel görünüm ve yetiştiği ortam.

- Gypsophila nodiflora (Boiss.) Barkoudah Wentia 9:153, t.17 f.23-30 (1962), (Şekil 3).

Çok yıllık, gövde dik, 30-100 cm, üst kısımlar glandular tüylü. Yapraklar spatulat, 2-7 cm, Çiçek kümesi seyrek ve kapitat, brakte lanseolat, salg1 tüylü. Çiçek sapı yok. Sepal tüpsü 6-9 mm, salg1 tüylü, dişli. Petaller pembe renkte, 12-18 mm. Stilus 2 tane ve 5-8 $\mathrm{mm}$. Meyve küremsi, 5-6 mm. boyunda ve 4- 12 tohuma sahip.

- Tip örneği: Tip: C6 Malatya: Besni Malatya arası, 1835, Aucher 636.

- Toplanılan yer: C6 Kahramanmaraş: Türkoğlu, Kızıl Eniş Göleti kuzeyi, 650 m, K 37.349053º, D $36.777530^{\circ}$, YZK-2151.

- Çiçek açma zamanı: Mayıs-Haziran

- Yetişme ortamı: Serpantinli topraklar, Pinus pinea L. ormanı açıklıkları

- Yetişme yükseltisi: 850-1200 m.

- Çevresindeki taksonlar: Onosma frutescens Lam., Ankyropetalum reuteri Boiss. \& Hausskn, Dianthus floribundus Boiss., Medicago lupulina L., Thymbra spicata L., Paliurus spina-christi P. Mill.

- Endemizm durumu: Endemik

- Fitocoğrafik bölgesi: İran-Turan elementi

- Tehlike kategorisi: VU
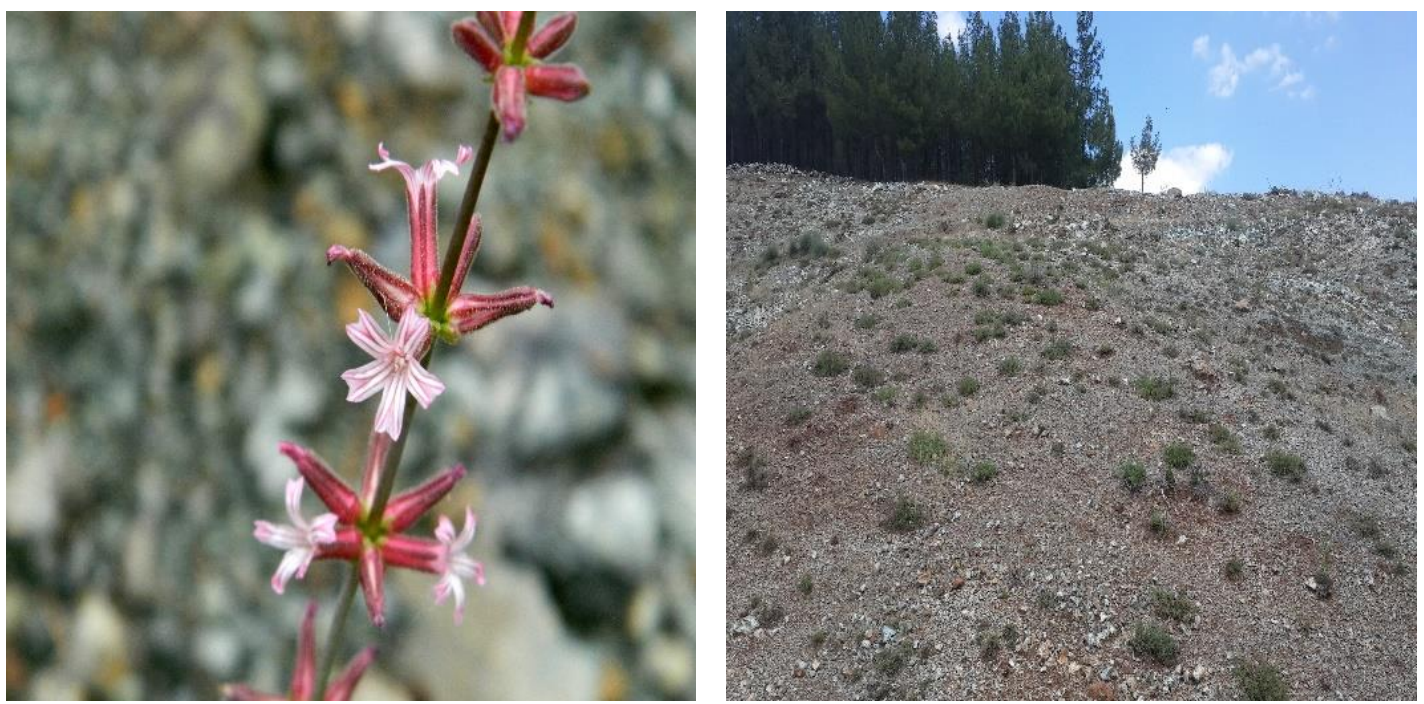

Şekil 3. Gypsophila nodiflora'ya ait genel görünüm ve yetiştiği ortam. 
- Salvia marashica A. İlçim, F. Celep \& Doğan, sp. Nova Ann. Bot. Fennici 46: 75-79 (2009), (Şekil 4).

Çok yıllık, tabanı odunsu, yarı çalı formunda. Birden fazla dik gövdeye sahip, 30-65 cm, kıvrık yada uzun yumuşak tüylü. Yapraklar parçalı, dar obovat 1.3-7-0.3-1.8 cm, sık ve uzun salgı tüylü. Yaprak sapı 0.7-3.0 cm, kıvrık uzun tüylü. Rasemöz şeklindeki çiçek kümesi 3-12 çiçekli, çiçek sapı 2-4 mm. Kaliks huni şeklinde ve iki dudakl1 $12-16 \mathrm{~mm}$, s1k uzun tüylü, corolla 20-28 mm, pembe renkte. Stilus $22-35 \mathrm{~mm}$ ve tüysüz. Nutletler globose-ovoid, $3 \mathrm{~mm}$ ve kahverengidir.

- Tip örneği: C6 Kahramanmaraş: Maksutlu köyü, 1450-1600 m, A. İlçim 995.

- Toplanılan yer: C6 Kahramanmaraş: Süleymanlı yolu, K:37.790398º, D:36. 782747º, YZK2112.

- Çiçek açma zamanı: Nisan-Mayıs

- Yetişme ortamı: Kireçli ve hareketli yamaçlar

- Yetişme yükseltisi: 1550-1600 m.

- Çevresindeki taksonlar: Pinus brutia Ten., Rhus coriaria L., Viola modesta Fenzl, Aethionema arabicum (L.) Andrz., Velezia rigida L., Silene nuncupanda Coode \& Cullen, Rheum ribes L.

- Endemizm durumu: Endemik

- Fitocoğrafik bölgesi: Akdeniz elementi

- Tehlike kategorisi: EN
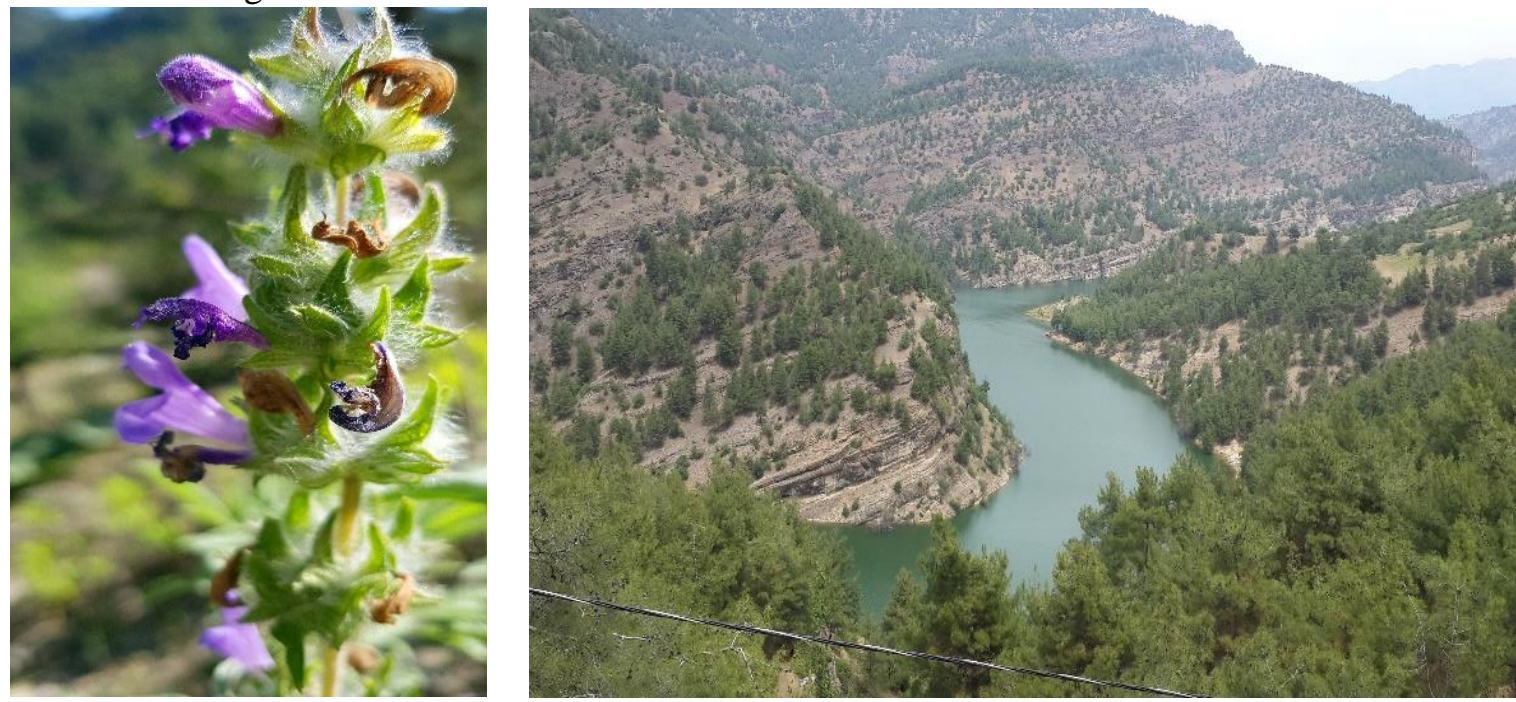

Şekil 4. Salvia marashica'ya ait genel görünüm ve yetiştiği ortam

- Stachys marashica A. İlçim, M. Çenet \& Dadand1, sp. Nova Ann. Bot. Fennici 45: 151-155 (2008), (Şekil 5).

Çok yıllık, taban yaprakları rozet şeklinde, yarı çalı formunda. Çiçekli gövde 9-25 cm, dallanma yok, tüysüz yada seyrek salg1 tüylü. Taban yapraklar oblong-eliptik, $0.8-6.5-0.3-3 \mathrm{~cm}$, tüysüz, kenarları dişli, petiol 1-4.5 cm. Gövde yaprakları uzun saplı. Vertisillatlar 2-4 adet, 3-14 çiçekli. Çiçek sapı 1$3 \mathrm{~mm}$. Sepal çan şeklinde 9-12 $\mathrm{mm}$, dişler $2.5-4 \mathrm{~mm}$, Petal 7-12 mm, tüysüz ve sarı renkte, nutletler oblong- ovoid, $2 \mathrm{~mm}$, açık kahverengi.

- Tip örneği: C6 Kahramanmaraş, Andırın, Efil ağzı, kireçli kayalar, 615 m, A. İlçim 1299.

- Toplanılan yer: C6 Kahramanmaraş: Başkonuş Dağı-Andırın arası, Efil ağzı bölgesi, 630 m,

- $\mathrm{K}: 37.493889^{\circ}$, D: $36.372578^{\circ}$, YZK-2201.

- Çiçek açma zamanı: Mayıs-Temmuz

- Yetişme ortamı: Kireçli ve hareketli yamaçlar

- Yetişme yükseltisi: 1550-1600 m.

- Çevresindeki taksonlar: Arabis caucasica Willd. subsp. brevifolia (DC.) Cullen, Sedum caespitosum (Cav.) DC., Anthemis hyalina DC., Polygala pruinosa Boiss. subsp. pruinosa

- Endemizm durumu: Endemik 
- Fitocoğrafik bölgesi: Akdeniz elementi

- Tehlike kategorisi: EN
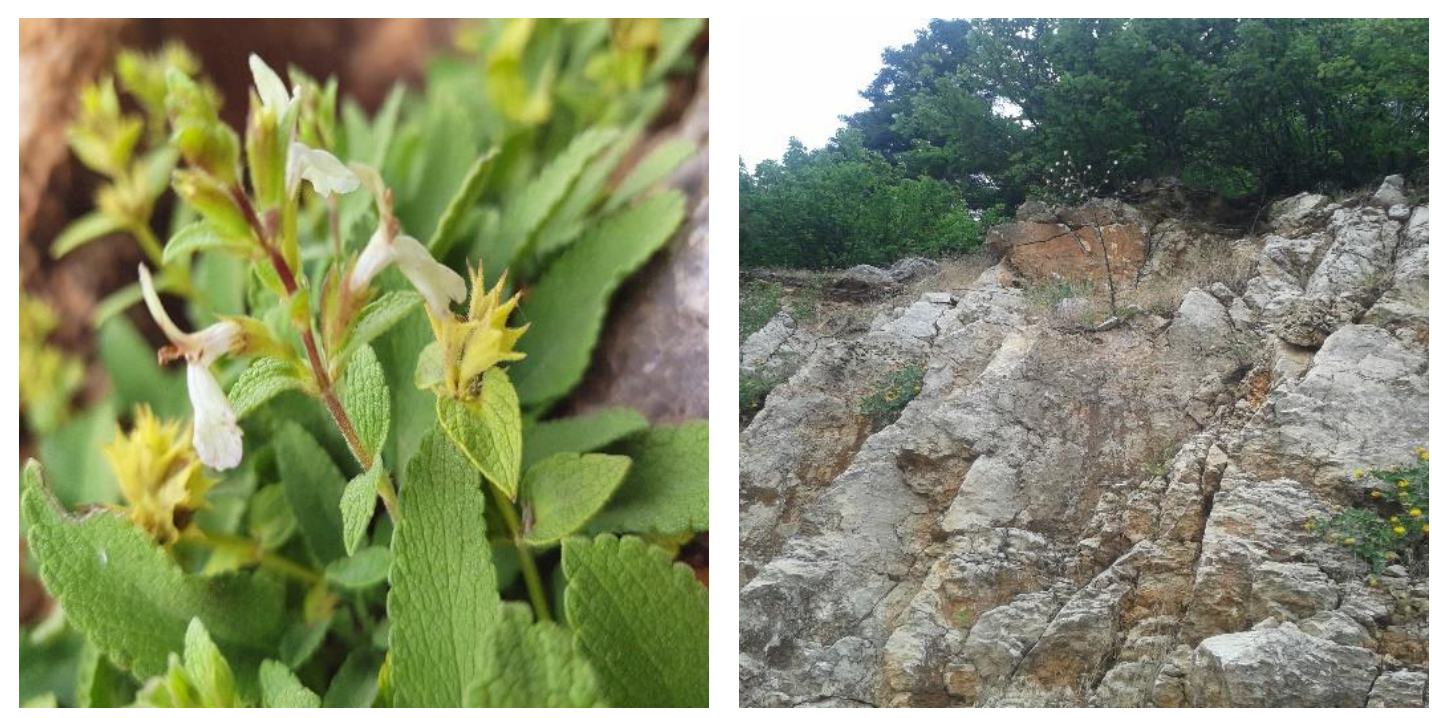

Şekil 5. Stachys marashica'ya ait genel görünüm ve yetiştiği ortam.

Dünyada gerçekleşen buzul çağları ekolojik yapıyı farklı şekillerde etkilemiş, canlı türlerinin yaşamasına imkan sağlayan ortamlar ve gelişen farklı iklim şartları bazı bitki türlerinin varlı̆̆ını sürdürmesine imkan sağlamıştır [20]. Anadolu'nun bu şartları sayesinde Ajuga relicta sınırlı alanda da olsa yaşamını halen devam ettirebilmektedir. Türkiye Florasında Kahramanmaraş-Ahırdağı bölgesinden kayıtlıdır, fakat bölgede yapılan farklı flora çalışmalarında türe rastlanamamıştır [21]. İlk toplanmasından (1907 yılı) sonra florada belirtilen lokalitenin yaklaşık $20 \mathrm{~km}$. güney batısında Çimen dağında tekrar tespit edilmiştir [6]. Astragalus akmanii, Kahramanmaraş-Ahırdağı bölgesinde çok sinırlı bir alanda ve oldukça az bireyle temsil edilmektedir. Yetişme ortamı şu an hayvancılık faaliyetlerinin yapıldığı bölge dışındadır bu durum türün korunmasına büyük katkı sağlamaktadır. Ancak alanın aynı zamanda mevcut ağaçlandırma (Cedrus libani A. Rich.) sahası olması gelecekte türün varlığını tehdit eden bir unsur haline gelecektir. Gypsophila nodiflora, Elazığ ve Malatya'da da yayılış göstermektedir. Çalışma alanında türün toplandığ 1 lokalite serpantinli toprak yapısındadır. Güney bakıda ve sıcaklık değerlerinin yüksek olması da bitki yoğunluğunun azalmasına neden olmaktadır. Tür sahip olduğu morfolojik yapı sayesinde alanda rekabet gücüne sahiptir. Ancak birey sayısının sınırlı olması ve ekolojik koşullar gelecekteki varlığını sınırlayan önemli etkenlerdir. Salvia marashica'nın tip örneği Ahırdağı-Maksutlu bölgesidir, ancak Ceyhan Vadisi'nde yer alan bir kaç lokalitede de çok az bireyle temsil edilmektedir. Bu çalışmada örnekleri topladığımız lokaliteler tür için yeni olmasının yanı sıra kaliksin daha fazla tüylü olması ile dikkat çekmekle birlikte lokaliteye bağlı tür içi karakterler olarak değerlendirilmiştir [17]. Ayrıca türün yetiştiği ortam yaz mevsiminde olduça kurak geçmekte olup mevcut kumlu toprak yapısı ve verimsiz çiçeklerin çok fazla oluşu birey sayısını sınırlayan en önemli etkenlerdir. Stachys marashica, Andırın-Efil ağzı bölgesinde kireçli kayalar üzerinde çok az bireyle varlığını sürdürmektedir. İklim koşulları türün devamlılığı için uygun olsa da yetiştiği ortam bu durumu sınırlayan en önemli faktördür.

\section{SONUÇ}

$\mathrm{Bu}$ çalışmada, Ajuga relicta, Astragalus akmanii, Gypsophila nodiflora, Salvia marashica ve Stachys marashica türlerinin morfolojik, taksonomik özellikleri ve ekolojilerine ait bilgiler verilmiş, tehlike kategorileri belirtilmiştir. Türkiye Bitkileri Kırmızı Kitabına göre; A. relicta $(\mathrm{EN})$ kategorisinde, A. akmanii (CR) kategorisinde, G. nodiflora (VU) kategorisinde değerlendirilmiştir. Çalışmamız sonucunda bu türlere ait yeni IUCN tehdit kategorileri önerilmemiştir. S. marashica ve Stachys marashica türleri ise yayılış alanlarının $5000 \mathrm{~km}^{2}$ 'nin altında ve 5 lokasyondan az olarak tespit edilmesi nedeniyle EN kategorisinde değerlendirilmelidir. 
Biyoçeşitliliğin önemli unsurları olan bu türlerin gelecekte varlıklarını sürdürebilmeleri için detaylı anatomik, sitolojik ve karyolojik çalışmaların yanı sıra in situ ve ex situ koruma eylem planlarının da hazırlanarak uygulanması gereklidir.

\section{KAYNAKLAR}

[1] Davis P.H., (1965-1982). Flora of Turkey and East aegean Islands, Vol.1-9, Edinburg.

[2] Özhatay F.N., Kültür Ş., Gürdal M., (2011). Check List of Additional Taxa to the supplement Flora of Turkey-V. Turkish Journal Botany. 35: 589-624.

[3] Ekim T., Koyuncu M., Vural M., Duman H., Aytaç Z., Adıgüzel N., (2000). Türkiye Bitkileri Kırmızı Kitabı. Yüzüncü Yı1 Üniversitesi ve Türkiye Tabiatını Koruma Derneği, Ankara. 246s.

[4] Güner A., Aslan S., Ekim T., Vural M., Babaç M., (2012). Türkiye Bitkileri Listesi Damarlı Bitkiler. Nezahat Gökyiğit Botanik Bahçesi ve Flora Araştırmaları Derneği Yayını. İstanbul.

[5] Baytop T., (1999). Türkiye'de Bitkiler ile Tedavi. Nobel Tıp Kitapevi. 145 s.

[6] Varol Ö., İlçim A., Tatlı A., (1998). New Observation on Two Poorly Known Turkish Species. Thaiszia Kosice. 8, 53-56.

[7] Aytaç Z., Ekici M., Akan H., (2012). Astragalus L. Türkiye Bitkileri Listesi (Damarlı Bitkiler). İstanbul, Turkey: Nezahat Gökyiğit Botanic Garden and Floristics Research Society.

[8] Kocabaş Y.Z., İlçim, A., Çömlekçioğlu, N., (2014). Kahramanmaraş Başkonuş Dağı gevenleri (Astragalus spp.) ve önemi. III. Uluslararası Odun Dışı Orman Ürünleri Sempozyumu. 8-10 Mayıs 2014. Kahramanmaraş.

[9] Vural M., Subaşı Ü., Ayyıldız G., Samancı İ., (2017). Ankara İli Er Geveni (Astragalus bozakmanii) Tür Koruma Eylem Planı. Orman ve Su İşleri Bakanlığı Doğa Koruma ve Milli Parklar Genel Müdürlüğü, IX. Bölge Müdürlüğü-Ankara Şube Müdürlüğü.

[10] Davis P.H., Mill R.R. \& Tan K., (1988). Flora of Turkey and the East Aegean Islands, Vol. $\mathrm{X}$, Supplement, Edinburgh University Press, Edinburgh.

[11] Güner A., Özhatay N., Ekim T. \& Başer K.H.C., (2000). Flora of Turkey and the East Aegean Islands.Vol. XI, Supplement - II, Edinburgh University Press, Edinburgh.

[12] Özgökçe F, Özçelik H., (1999). Morfological, Taxonomical and Ecological Investigations on Gypsophila bitlisensis Barkoudah and Gypsophila elegans M. Bieb., 1st International Symposium on the Protection of Natural Environment \& Ehrami Karaçam, 295-313, Kütahya.

[13] Barkoudah Y., (1962). A Revision of Gypsophila, Bolanthus, Ankyropetalum and Phryna.Wentia, 9: 1-203.

[14] Walker J.B. \& Sytsma K.J., (2007). Staminal Evolution in the Genus Salvia (Lamiaceae): Molecular Phylogenetic Evidence for Multiple Origins of the Staminal Lever. Annales of Botany, 100, 375-391. 
[15] Marin P.D., Duletic S. \& Petkovic B., (1996). Nutlet Ornamentation in Selected Salvia L. Species (Lamiaceae). Flora Mediterranean. 6, 203-211.

[16] Ulubelen A., 2003. Cardioactive and antibacterial terpenoids from some Salvia species. Phytochemistry. 64, 395-399.

[17] İlçim A., Celep F. \& Doğan M., (2009). Salvia marashica (Lamiaceae), a new species from Turkey. Annales Botanical Fennici, 45, 75-79.

[18] İlçim A., Çenet M. \& Dadandı M.Y.,(2008). Stachys marashica (Lamiaceae), A new species from Turkey, Ann. Bot. Fennici, 45: 151-155.

[19] Altınayar G., Bitki Bilimi Terimleri Sözlüğü, (1987). DSİ Basım İşletme Müdürlüğü Matbaas1, 308s.

[20] Şekercioğlu Ç.H., Anderson S., Akçay E., Bilgin R., Can Ö.E., Semiz G., Tavşanoğlu Ç., Yokes M.B., Soyumert A., İpekdal K., Sağlam I.K., Yücel M., Dalfes H.N., (2011). Turkey's globally important biodiversity in crisis. Biological Conservations, 144, 27522769.

[21] Duman H., Aytaç Z., (1994). Ahır, Berit, Binboğa ve Öksüz Dağları (KahramanmaraşKayseri) Yüksek Dağ Stebinin Flora ve Vejetasyonu, TUBİTAK, TBAG-940, Ankara, 186s. 